\title{
Effects of fesoterodine on
} the pharmacokinetics and pharmacodynamics of warfarin in healthy volunteers

\author{
Bimal Malhotra, ${ }^{1}$ Christine Alvey, ${ }^{2}$ Jason Gong, ${ }^{1}$ Xiaoxi Li, ${ }^{2}$ \\ Gregory Duczynski ${ }^{2} \&$ Kuan Gandelman ${ }^{1}$ \\ 30 March 2011 \\ Accepted Article \\ 15 April 2011
}

${ }^{1}$ Pfizer Inc., New York, NY and 'Pfizer Inc., New London, CT, USA

Dr Bimal Malhotra MD, Pfizer Inc., 685 3rd Ave., New York, NY 10017, USA.

Tel.: +1 2127334723

Fax: +1 6464768949

E-mail: bimal.k.malhotra@pfizer.com

Keywords

antimuscarinic, drug-drug interactions, fesoterodine, overactive bladder, pharmacokinetics, warfarin

Received

3 August 2010

Accepted

\section{WHAT IS ALREADY KNOWN ABOUT THIS SUBJECT \\ - Drug-drug interactions with warfarin are common with potentially harmful consequences. Preclinical in vitro studies suggest that fesoterodine or 5-hydroxymethyl tolterodine are not likely to affect warfarin metabolism, but a lack of interaction has not been demonstrated in a clinical study.}

\section{WHAT THIS STUDY ADDS}

- This study shows that the pharmacokinetics and pharmacodynamics of warfarin $25 \mathrm{mg}$ in healthy adults are unaffected by fesoterodine $8 \mathrm{mg}$, and that co-administration of warfarin $25 \mathrm{mg}$ and fesoterodine $8 \mathrm{mg}$ is safe and well tolerated.

\section{AIMS}

To confirm the lack of an interaction of fesoterodine $8 \mathrm{mg}$ with warfarin pharmacokinetics and pharmacodynamics in healthy adults.

\section{METHODS}

In this open-label, two-treatment, crossover study, subjects $(n=14)$ aged 20-41 years with normal prothrombin time (PT) and International Normalized Ratio (INR) were randomized to receive a single dose of warfarin $25 \mathrm{mg}$ alone in one period and fesoterodine $8 \mathrm{mg}$ once daily on days 1-9 with a single dose of warfarin $25 \mathrm{mg}$ co-administered on day 3 in the other period. There was a 10-day washout between treatments. Pharmacokinetic endpoints were area under the plasma concentration-time curve from time 0 to infinity $(\operatorname{AUC}(0, \infty))$, maximum plasma concentration $\left(C_{\max }\right)$, AUC from time 0 to the time of the last quantifiable concentration (AUC $\left(0\right.$,last)), time to $C_{\max }\left(t_{\max }\right)$, and half-life $\left(t_{1 / 2}\right)$ for $S$ - and R-warfarin. Pharmacodynamic endpoints were area under the INR-time curve $\left(A \cup C_{\mathbb{I N R}}\right)$, maximum INR (INR $\left.R_{\max }\right)$, area under the PT-time curve (AUC $\left.C_{P T}\right)$ and maximum PT (PT $\left.T_{\text {max }}\right)$.

\section{RESULTS}

Across all pharmacokinetic and pharmacodynamic comparisons, the point estimates of treatment ratio (warfarin co-administered with fesoterodine vs. warfarin alone) were $92-100 \%$. The $90 \%$ confidence intervals for the ratios of the adjusted geometric means were contained within $(80 \%, 125 \%)$. There were no clinically relevant changes in laboratory tests, vital signs or ECG recordings.

\section{CONCLUSIONS}

The pharmacokinetics and pharmacodynamics of warfarin $25 \mathrm{mg}$ in healthy adults are unaffected by fesoterodine $8 \mathrm{mg}$. Concomitant administration of fesoterodine and warfarin was well tolerated. 


\section{Introduction}

The prevalence of overactive bladder (OAB) is known to increase with advancing age [1]. Antimuscarinics are considered first-line pharmacological treatment for $O A B$ symptoms [2]. Fesoterodine is a non-selective antimuscarinic agent that is approved for once daily oral administration at 4-mg and 8-mg doses for the treatment of $O A B$ symptoms [3-5]. Fesoterodine is not detectable in plasma after oral administration [6], which reflects a rapid and extensive conversion to 5-hydroxymethyl tolterodine (5-HMT) by non-specific esterases [7]. 5-HMT exhibits linear pharmacokinetics (PK) across a wide range of fesoterodine doses $(4-28 \mathrm{mg})$, with maximum plasma concentrations achieved approximately $5 \mathrm{~h}$ after administration of fesoterodine [8]. The elimination of 5-HMT is mediated by multiple pathways, including renal excretion and metabolism to form inactive metabolites via cytochrome P450 (CYP) isozymes, CYP3A4 and CYP2D6 $[8,9]$.

Because the prevalence of $O A B$ increases with age [1], many individuals receiving fesoterodine for $O A B$ will also be receiving medication for concomitant, non-OAB-related conditions. Controlled clinical trials are needed to assess the effects of fesoterodine on the PK and pharmacodynamic (PD) profiles of drugs commonly co-administered in the older individuals. Warfarin is a widely used anticoagulant administered to patients with atrial fibrillation as a prophylaxis against thrombosis [10]. Warfarin is approved for administration as a 50:50 racemic mixture of two active enantiomers, S-warfarin and R-warfarin [11]. Warfarin has a narrow therapeutic index and its anticoagulant response can be affected by drug interactions that interfere with its absorption or metabolic clearance [12]. S-warfarin, the more pharmacologically active enantiomer, is primarily metabolized by CYP2C9, while the less active R-warfarin enantiomer is largely metabolized by CYP3A4 and CYP1A2 [11]. Drug-drug interactions with warfarin are common with potentially harmful consequences; competitive inhibition of S-warfarin metabolism enhances anticoagulation effects, whereas agents that enhance rates of warfarin metabolism diminish anticoagulation effects [11].

Preclinical in vitro studies suggest that fesoterodine or $5-\mathrm{HMT}$ are not likely to affect warfarin metabolism [3,4]. Because of the narrow therapeutic index of warfarin, this clinical study was conducted to confirm the preclinical results that suggested the lack of an effect of fesoterodine or 5-HMT on CYP3A4, $1 \mathrm{~A} 2$ and 2C9, the enzymes responsible for the metabolism of R- and S-warfarin. In warfarin drug interaction studies, warfarin is administered as a single large dose (e.g. $25 \mathrm{mg}$ ) in the absence or presence of steady-state treatment of the drug that has potential to interact with warfarin; the use of a higher single dose of warfarin allows greater potential to detect an interaction as well as reduces the exposure of healthy volunteers to a prolonged period of anticoagulation. In some published studies, the interaction of a drug with warfarin has been assessed by administration of a single lower $(10-15 \mathrm{mg})$ oral dose of warfarin $[13,14]$. A $7 \%$ decrease in S-warfarin AUC could be demonstrated after a single 10-mg dose of warfarin. However, this study did not show a PD effect on prothrombin time (PT) [14]. Therefore, the lower therapeutic doses of warfarin, administered as single doses, may not be sufficient to demonstrate a PD interaction in a genetically heterogenous population. Consequently, a single $25-\mathrm{mg}$ dose of warfarin was chosen to evaluate the effects of fesoterodine on the PK and PD of warfarin. The specific aims of this study were to determine (i) the PK of R- and S-warfarin, (ii) the PD (anticoagulant activity) and (iii) safety and tolerability in healthy subjects when a single supratherapeutic $(25 \mathrm{mg})$ dose of warfarin is administered alone or concomitantly with fesoterodine $8 \mathrm{mg}$ once daily at steady state.

\section{Methods}

\section{Inclusion/exclusion criteria}

Eligible subjects $(n=14)$ included healthy adults aged 18-55 years with PT/International Normalized Ratio (INR), partial thromboplastin time and plasma protein $\mathrm{C}$ and $\mathrm{S}$ activity (functional) within the normal range. Subjects were excluded if they were receiving warfarin for treatment of active thromboembolic events, had a history of coagulation abnormalities, had a presence of occult blood in stool, had a history or evidence of clinically significant urological disease, had narrow angle glaucoma or had a condition affecting drug absorption. Additional key exclusion criteria were a positive urine drug test, alcohol consumption [i.e. consumption exceeding 7 drinks/week for females or 14 drinks/week for males within 6 months of screening; 1 drink was defined as $5 \mathrm{oz}(150 \mathrm{ml})$ of wine, $12 \mathrm{oz}(360 \mathrm{ml})$ of beer, or $1.5 \mathrm{oz}(45 \mathrm{ml})$ of hard liquour] or tobacco use (i.e. use of tobacco- or nicotine-containing products in excess of the equivalent of 5 cigarettes day ${ }^{-1}$ ); and consumption of grapefruit, grapefruit-related, cranberry or cranberry-related juice within 7 days of receiving study drug.

\section{Study design}

This open-label, randomized, crossover study consisted of two treatment periods. During one period, subjects received a single dose of warfarin $25 \mathrm{mg}$ alone on day 1 (treatment A); during the other period, subjects received fesoterodine $8 \mathrm{mg}$ once daily on days $1-9$, with a single supratherapeutic dose of warfarin $25 \mathrm{mg}$ co-administered on day 3 (treatment B). Subjects were randomized to one of two treatment sequences: treatment $A$ followed by treatment $B$ or treatment $B$ followed by treatment $A$. There was at least a 10-day washout between warfarin doses in the two treatment periods. 
This study was conducted in compliance with the Declaration of Helsinki and in compliance with all International Conference on Harmonization Good Clinical Practice Guidelines. The final protocol was approved by the appropriate Institutional Review Board. All subjects provided written informed consent prior to entering the study. The drug/molecular target nomenclature included conforms to the British Journal of Pharmacology's Guide to Receptors and Channels [15].

\section{Pharmacokinetic evaluations}

Blood samples for determination of R-warfarin and $\mathrm{S}$-warfarin concentrations in plasma were collected before each warfarin dose and at $0.5,1,2,4,8,12,24,36,48,72,96$, 120, 144 and $168 \mathrm{~h}$ post dose. Plasma samples were analysed at WuXi AppTec (Shanghai, China) using a validated sensitive and specific high-performance liquid chromatography-tandem mass spectrometry method in compliance with the sponsor's standard operating procedures. Plasma samples were stored at approximately $-20^{\circ} \mathrm{C}$ until analysis and assayed within 92 days of established stability data generated during validation. Calibration standard responses were linear from 2.5 to $2500 \mathrm{ng} \mathrm{ml}^{-1}$ for both active enantiomers. Clinical specimens below the lower limit of quantification of $2.5 \mathrm{ng} \mathrm{ml}^{-1}$ were recorded as $0 \mathrm{ng} \mathrm{ml}^{-1}$ for analysis. The between-day assay accuracy, expressed as per cent relative error, for quality control (QC) concentrations, ranged from $0.9 \%$ to $7.0 \%$ (R-warfarin) and $-1.3 \%$ to $6.0 \%$ (S-warfarin) for the low, medium low, medium high, high and diluted QC concentrations. Assay precision, expressed as the between-day coefficient of variation [CV (\%)] of the mean estimated concentration of QC samples, was 5.0\% (R-warfarin) and 4.5\% (S-warfarin) for the low $\left(7.50 \mathrm{ng} \mathrm{ml}^{-1}\right)$, medium low (100 $\mathrm{ng} \mathrm{ml}^{-1}$ ), medium high (1000 $\mathrm{ng} \mathrm{ml}^{-1}$ ), high (1900 $\mathrm{ng} \mathrm{ml}^{-1}$ ) and dilution (7500 $\mathrm{ng} \mathrm{ml}^{-1}$ ) QC concentrations.

Pharmacokinetic parameters for S- and R-warfarin were calculated from the plasma concentration-time data using standard non-compartmental methods. Primary PK endpoints (for S- and R-warfarin) were area under the plasma concentration-time curve from time zero to infinity $(\mathrm{AUC}(0, \infty))$ and maximum plasma concentration $\left(C_{\max }\right)$. Secondary endpoints (for S- and R-warfarin) were area under the plasma concentration-time profile from time 0 to the time of the last quantifiable concentration $(A \cup C(0$, last $))$, time to $C_{\max }\left(t_{\max }\right)$, and half-life $\left(t_{1 / 2}\right)$.

\section{Pharmacodynamic evaluations}

Warfarin PD (anticoagulation activity) was monitored by assessment of the INR, which corresponds to the PT ratio corrected for an individual thromboplastin reagent using the International Sensitivity Index (ISI). Although INR has replaced $\mathrm{PT}$ in clinical practice for monitoring of patients receiving warfarin, $\mathrm{PT}$ was also used for $\mathrm{PD}$ analysis in this study because PT is less variable than the INR. Blood samples for R-warfarin and S-warfarin PD analyses were collected before each warfarin dose and at $12,24,36,48,60$, $72,96,120,144$ and $168 \mathrm{~h}$ post dose. Primary PD endpoints were area under the INR vs. time curve $\left(A \cup C_{\mathbb{I N R}}\right)$ and maximal INR $\left(I N R_{\max }\right)$. Secondary endpoints were area under the PT vs. time curve (AUC $C_{\mathrm{PT}}$ ) and maximal PT (PT max $)$.

\section{Safety evaluations}

Safety was assessed by adverse event (AE) monitoring, laboratory evaluations, physical examinations, 12-lead ECG testing and vital sign evaluations.

\section{Statistics}

Study populations Twelve completed subjects would provide $\geq 90 \%$ power to show equivalence in warfarin PK and PD with or without fesoterodine (assuming a 10\% within-subject CV and a true ratio of 1.0). The PK concentration population included subjects who were randomized and treated and had $\geq$ one concentration measurement and $\geq$ one treatment period. The PK parameter analysis population was defined as all subjects randomized and treated who had $\geq$ one primary PK endpoint measured in $\geq$ one treatment period. The safety population consisted of all subjects who received $\geq$ one dose of study drug.

$P K$ and $P D$ analyses Natural log transformed PK analyses $\left(A \cup C(0, \infty), C_{\max }\right)$ and $P D$ analyses $\left(A \cup C_{I N R}\right.$ and $\left.I N R_{\max }\right)$ were analysed using a mixed effect model with sequence, period and treatment as fixed effects and subject within sequence as a random effect. Estimates of adjusted mean differences between warfarin co-administered with fesoterodine (test treatment) and warfarin alone (reference treatment) and corresponding $90 \%$ confidence intervals (Cls) were obtained. Adjusted mean differences and 90\% $\mathrm{Cls}$ for the differences were exponentiated to provide estimates of the ratio (test: reference) of adjusted geometric means and $90 \% \mathrm{Cls}$ for the ratios. Lack of treatment interaction was concluded if the $90 \% \mathrm{Cls}$ for the ratio of adjusted geometric means for $A \cup C(0, \infty), C_{\max }, A \cup C_{\text {INR }}$ and $I N R_{\max }$ fell within the bioequivalence acceptance range $(80 \%, 125 \%)$. AUC $(0, \infty), C_{\max }$ AUC(0,last), $t_{\max ,} t_{1 / 2}, \mathrm{AUC}_{\text {INR, }}$

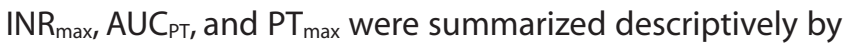
treatment.

Safety analyses Adverse events occurring within 7 days of treatment discontinuation (including temporary cessations) were recorded as treatment-emergent. Events occurring in non-treatment periods (washout or follow-up) were also counted as treatment-emergent and attributed to the previous treatment.

\section{Results}

All subjects were healthy men between 20 and 41 years of age (mean age 30.8 years) with an average weight of $77 \mathrm{~kg}$ 


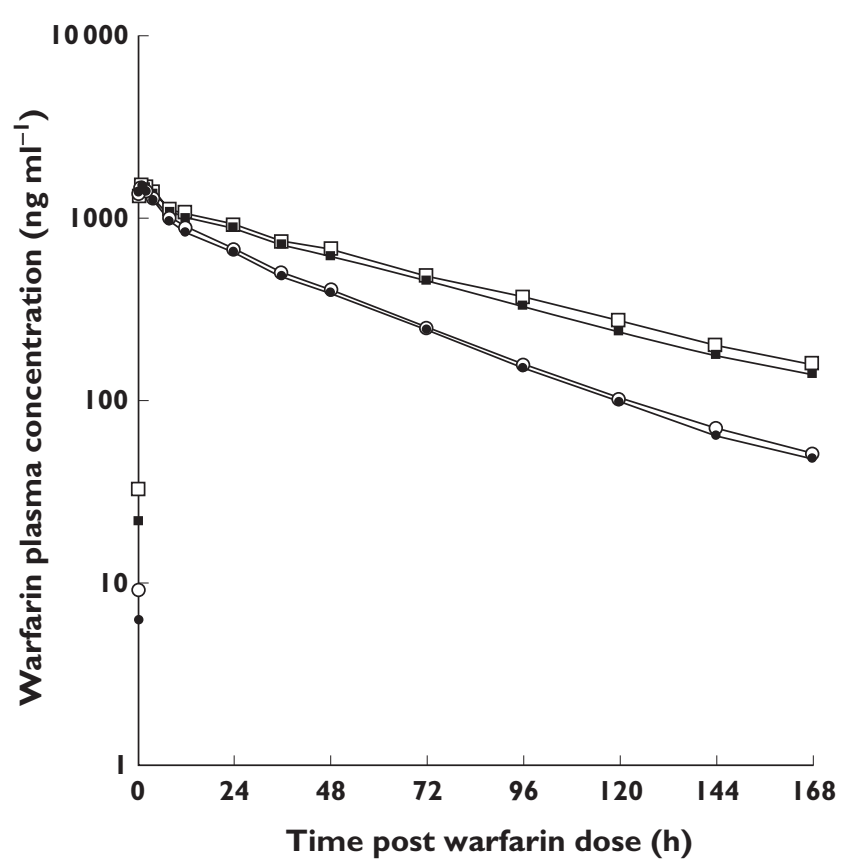

Figure 1

Mean plasma concentration-time profiles for R-warfarin and S-warfarin in the absence and presence of fesoterodine in 14 healthy subjects. Warfarin was administered as a single $25-\mathrm{mg}$ dose alone or as a single 25 -mg dose on day 3 of the 10-day treatment period during which fesoterodine $8 \mathrm{mg}$ was administered on days 1-9. R-warfarin (warfarin alone) (- $\square$-); R-warfarin (warfarin with fesoterodine) (- -); S-warfarin (warfarin alone) (-O-); S-warfarin (warfarin with fesoterodine) (-

(range $55.0-96.0 \mathrm{~kg}$ ) and body mass index of $24.5 \mathrm{~kg} \mathrm{~m}^{-2}$ (range $19.3-28.6 \mathrm{~kg} \mathrm{~m}^{-2}$ ). All subjects received both treatments and completed the study.

\section{Pharmacokinetic outcomes}

As shown in Figure 1, mean plasma concentration-time curves for R-warfarin and S-warfarin were similar after administration of warfarin alone and after coadministration of warfarin and fesoterodine. The $\operatorname{AUC}(0, \infty)$ and $C_{\max }$ of R-warfarin decreased by approximately $8 \%$ and $5 \%$, respectively, following concomitant administration of fesoterodine, compared with a $4 \%$ decrease in both $\operatorname{AUC}(0, \infty)$ and $C_{\max }$ for S-warfarin (Table 1). Notably, the upper and lower limits of the $90 \% \mathrm{Cl}$ for the ratios of $\operatorname{AUC}(0, \infty)$ and $C_{\max }$ for co-administration of fesoterodine with warfarin vs. warfarin alone were in all cases within the bioequivalence acceptance range (80\%-125\%). There was no interactive effect on warfarin PK. There were modest decreases in the $\mathrm{AUC}(0$, last $)$ and $t_{1 / 2}$ of R-warfarin (7\% and $6 \%$, respectively) and S-warfarin ( $4 \%$ and $3 \%$, respectively) following co-administration with fesoterodine (Table 1). Concomitant administration of fesoterodine with warfarin did not impact the $t_{\max }$ of R- and S-warfarin (Table 1).

\section{Table 1}

Summary of warfarin PK and PD results

\begin{tabular}{|c|c|c|}
\hline Parameter & $\begin{array}{l}\text { Warfarin }+ \text { fesoterodine } \\
n=14\end{array}$ & $\begin{array}{l}\text { Warfarin alone } \\
n=14\end{array}$ \\
\hline \multicolumn{3}{|l|}{ R-warfarin } \\
\hline $\operatorname{AUC}(0, \infty)\left(\mu \mathrm{g} \mathrm{ml}^{-1} \mathrm{~h}\right)$ & $88.2(30)$ & $96.3(30)$ \\
\hline $\operatorname{AUC}(0$, last $)\left(\mu \mathrm{g} \mathrm{ml}^{-1} \mathrm{~h}\right)$ & $78.2(24)$ & $83.9(24)$ \\
\hline$C_{\max }\left(\mu \mathrm{g} \mathrm{ml}^{-1}\right)$ & $1.60(24)$ & $1.69(21)$ \\
\hline$t_{\max }(\mathrm{h})$ & $1.0(0.5-2.0)$ & $1.0(0.5-12.0)$ \\
\hline$t_{1 / 2}(h)$ & $53.1(27)$ & $56.5(26)$ \\
\hline \multicolumn{3}{|l|}{ S-warfarin } \\
\hline $\operatorname{AUC}(0, \infty)\left(\mu \mathrm{gl}^{-1} \mathrm{~h}\right)$ & $53.2(25)$ & $55.4(23)$ \\
\hline AUC), last) ( $\left.\mu \mathrm{g} \mathrm{ml}^{-1} \mathrm{~h}\right)$ & $51.0(22)$ & $52.9(20)$ \\
\hline$C_{\max }\left(\mu \mathrm{g} \mathrm{ml}^{-1}\right)$ & $1.62(24)$ & $1.69(22)$ \\
\hline$t_{\max }(\mathrm{h})$ & $1.0(0.5-2.0)$ & $1.0(0.5-4.0)$ \\
\hline$t_{1 / 2}(\mathrm{~h})$ & $36.2(19)$ & $37.3(20)$ \\
\hline \multicolumn{3}{|l|}{ INR } \\
\hline$A U C_{I N R}$ & 236.82 & 236.25 \\
\hline $\mathbf{I N R}_{\max }$ & 1.94 & 1.99 \\
\hline \multicolumn{3}{|l|}{ PT } \\
\hline$A U C_{P T}$ & 2356.24 & 2317.80 \\
\hline $\mathrm{PT}_{\max }$ & 19.81 & 19.26 \\
\hline
\end{tabular}

Geometric mean (geometric \%CV) for all except: median (range) for $t_{\text {max; }}$ arithmetic mean $(\% \mathrm{CV})$ for $t_{1 / 2}$.

\section{Table 2}

Statistical analysis of the effects of fesoterodine co-administration on warfarin PK and PD

\begin{tabular}{|c|c|c|c|}
\hline Parameter & $\begin{array}{l}\text { Treatmen } \\
\text { (warfarin } \\
\text { Point } \\
\text { estimate } \\
\text { (\%) }\end{array}$ & $\begin{array}{l}90 \% \text { confidence } \\
\text { interval }\end{array}$ & $\begin{array}{l}\text { Meets BE } \\
\text { criterion* }\end{array}$ \\
\hline \multicolumn{4}{|l|}{ R-Warfarin } \\
\hline AUC & 91.61 & $88.34,95.01$ & $\checkmark$ \\
\hline$C_{\max }$ & 94.25 & $88.05,100.90$ & $\checkmark$ \\
\hline \multicolumn{4}{|l|}{ S-Warfarin } \\
\hline AUC & 96.04 & $91.77,100.51$ & $\checkmark$ \\
\hline$C_{\max }$ & 96.29 & $88.41,104.87$ & $d$ \\
\hline \multicolumn{4}{|l|}{ INR } \\
\hline$A U C_{I N R}$ & 100.24 & $96.39,104.25$ & $\checkmark$ \\
\hline$I \mathbf{N R}_{\max }$ & 97.29 & $89.16,106.17$ & $\checkmark$ \\
\hline
\end{tabular}

* $90 \%$ Cl within $(80 \%, 125 \%)$. BE, bioequivalence.

\section{Pharmacodynamic outcomes}

Co-administration of fesoterodine with warfarin did not affect warfarin $A \cup C_{\text {INR, }}, I N R_{\max }, A U C_{P T}$ and $\mathrm{PT}_{\max }$ (Table 2). Notably, the upper and lower limits of the $90 \% \mathrm{Cl}$ for the ratios of $A U C_{I N R}$ and INR $R_{\max }$ for fesoterodine and warfarin compared with warfarin alone were in all cases within the bioequivalence acceptance range (80\%-125\%). There was no interactive effect on warfarin PD.

\section{Safety outcomes}

Following co-administration of fesoterodine and warfarin, eight subjects (57.1\%) experienced a total of 20 all causal- 
ity AEs; 17 of these were considered treatment-related. Following administration of warfarin alone, three subjects (21.4\%) experienced a total of nine all causality AEs; seven were considered treatment-related. Dry eye, diarrhoea and headache occurred in two subjects each in the fesoterodine and warfarin group. All other adverse events were reported in one subject each. Of the 29 AEs reported, 28 were of mild intensity. There were no dose reductions or temporary discontinuations related to AEs.

As expected, the most common abnormal laboratory finding was an increase in PT, which was observed after treatment with warfarin with or without co-administration of fesoterodine. No abnormal laboratory findings were considered clinically relevant or reported as AEs. There were no clinically relevant changes from baseline in vital signs.

\section{Discussion}

Because the prevalence of $O A B$ increases with advancing age [1], it is likely that patients being treated for the condition may also be receiving medication to treat concomitant conditions, including warfarin. Fesoterodine and $\mathrm{R}$-warfarin, the less active enantiomer of the widely used anticoagulant warfarin, are CYP3A4 substrates. Warfarin is known to have a narrow therapeutic index. Thus, we evaluated the effects of fesoterodine on the PK and PD of 50:50 racemic warfarin ( $\mathrm{R}$ - and S-enantiomers) in healthy subjects, as well as the safety and tolerability associated with concurrent administration of these drugs. Results of the present study demonstrated that fesoterodine had no clinically meaningful effect on the PK of R- or S-warfarin or the PD of warfarin, and that concomitant administration of the drugs was well tolerated. The results of this clinical study also show concordance with the in vitro studies that suggested fesoterodine and 5-HMT do not interact with CYP3A4, $1 A 2$ and 2C9, the enzymes responsible for the metabolism of R- and S-warfarin. The results of this study suggest that dose adjustment of warfarin may not be necessary when co-administered with fesoterodine. However, only a single dose of warfarin was evaluated in this study. The anticoagulant response to warfarin is affected by a number of variables and periodic dose adjustment of warfarin may be necessary even in the absence of concomitant medication.

There was an inherent limitation to this study in that this population of healthy volunteers may not be representative of patients with atrial fibrillation receiving warfarin therapy. In addition, the evaluation of the safety and tolerability of fesoterodine administered without warfarin was not possible due to the design of this study.

In conclusion, when comparing warfarin coadministered with fesoterodine $v s$. warfarin alone, the estimated treatment ratio for $\operatorname{AUC}(0, \infty)$ and $C_{\max }$ was $92 \%$ and $94 \%$, respectively (R-warfarin) and $96 \%$ and $96 \%$, respec- tively (S-warfarin). The estimated treatment ratio (warfarin co-administered with fesoterodine vs. warfarin alone) for $A U C_{I N R}$ and $I N R_{\max }$ was $100 \%$ and $97 \%$, respectively. The $90 \%$ confidence intervals for the ratios of the adjusted geometric means were contained within $(80 \%, 125 \%)$ for each of the PK and PD comparisons. The results of this study indicated that there was no interaction of fesoterodine with the PK and the anticoagulant activity of warfarin. Concomitant administration of fesoterodine and warfarin was well tolerated. These data suggest that no dose adjustment is needed during concomitant use of warfarin with fesoterodine.

\section{Competing Interests}

$\mathrm{BM}, \mathrm{CA}, \mathrm{JG}, \mathrm{GD}$ and $\mathrm{KG}$ are Pfizer employees and own Pfizer stock. There are no other competing interests to declare.

This study was funded by Pfizer Inc. Editorial support was provided by Nancy Sheridan at Complete Healthcare Communications, Inc. and was funded by Pfizer Inc.

\section{REFERENCES}

1 Irwin DE, Milsom I, Hunskaar S, Reilly K, Kopp Z, Herschorn S, Coyne K, Kelleher C, Hampel C, Artibani W, Abrams P. Population-based survey of urinary incontinence, overactive bladder, and other lower urinary tract symptoms in five countries: results of the EPIC study. Eur Urol 2006; 50: 1306-15.

2 Andersson KE, Chapple CR, Cardozo L, Cruz F, Hashim H, Michel MC, Tannenbaum C, Wein AJ. Pharmacological treatment of overactive bladder: report from the International Consultation on Incontinence. Curr Opin Urol 2009; 19: 380-94.

3 Toviaz (Fesoterodine Fumarate). Full prescribing information. New York, NY: Pfizer Inc., 2010.

4 European Medicines Agency (EMEA). EPARs for authorized medicinal products for human use. European Public Assessment Report for Toviaz (Product Information). Updated August 2009. Available at http://www.emea. europa.eu/humandocs/Humans/EPAR/toviaz/toviaz.htm. (last accessed 20 October 2009).

5 Ellsworth P. Fesoterodine for the treatment of urinary incontinence and overactive bladder. Ther Clin Risk Manag 2009; 5: 869-76.

6 Cawello W, Auer S, Hammes W, Sachse R, Horstmann R. Multiple dose pharmacokinetics of fesoterodine in human subjects. Arch Pharmacol 2002; 365 (Suppl. 1): R110.

7 Michel MC. Fesoterodine: a novel muscarinic receptor antagonist for the treatment of overactive bladder syndrome. Expert Opin Pharmacother 2008; 9: 1787-96.

8 Cole P. Fesoterodine, an advanced antimuscarinic for the treatment of overactive bladder: a safety update. Drugs Future 2004; 29: 715-20. 
9 Kaplan SA, Roehrborn CG, Chancellor M, Carlsson M, Bavendam T, Guan Z. Extended-release tolterodine with or without tamsulosin in men with lower urinary tract symptoms and overactive bladder: effects on urinary symptoms assessed by the International Prostate Symptom Score. BJU Int 2008; 102: 1133-9.

10 Kottkamp H, Hindricks G, Breithardt G. Role of anticoagulant therapy in atrial fibrillation. J Cardiovasc Electrophysiol 1998; 9: (8 Suppl.): S86-96.

11 Kaminsky LS, Zhang ZY. Human P450 metabolism of warfarin. Pharmacol Ther 1997; 73:67-74.

12 Hirsh J, Dalen J, Anderson DR, Poller L, Bussey H, Ansell J, Deykin D. Oral anticoagulants: mechanism of action, clinical effectiveness, and optimal therapeutic range. Chest 2001; 119: (1 Suppl.): 8S-21S.

13 Stirling Y, Howarth DJ, Stockley R, Bland R, Towler CM, Harding SM. Comparison of the bioavailabilities and anticoagulant activities of two warfarin formulations. $\mathrm{Br} \mathrm{J}$ Haematol 1982; 51:37-46.

14 Lilja JJ, Backman JT, Neuvonen PJ. Effects of daily ingestion of cranberry juice on the pharmacokinetics of warfarin, tizanidine, and midazolam - probes of CYP2C9, CYP1A2, and CYP3A4. Clin Pharmacol Ther 2007; 81: 833-9.

15 Alexander SPH, Mathie A, Peters JA. Guide to Receptors and Channels (GRAC), 4th edition. Br J Pharmacol 2009; 158 (Suppl. 1):S1-S254. 